\title{
As forças produtivas em Marx e o surpreendente século $\mathrm{XX}$
}

Benedito Rodrigues de Moraes Neto ${ }^{1}$

Resumo: Procura-se, através de avaliação crítica das contribuições de Benjamin Coriat e Ruy Fausto, esclarecer como a emergência histórica do taylorismo-fordismo teria dificultado a compreensão da relevância da análise das forças produtivas feita por Marx para o entendimento da evolução das forças produtivas ao longo do século XX. Argumenta-se que, sendo o taylorismofordismo na verdade uma "reinvenção da manufatura", ele não se ajusta ao conceito de máquina para Marx, e que a não observação desse fato teria ocasionado as dificuldades observadas nos autores estudados. Essas dificuldades se manifestam na proposta (nem sempre explicitada) de prescindir dos Grundrisse e de O Capital, ou de apenas O Capital, para dar conta da natureza das forças produtivas no presente e no futuro, a qual se procura tratar criticamente.

Palavras-chave: Forças produtivas; análise marxista; manufatura; maquinaria; taylorismo-fordismo.

\section{The Marxian analysis of productive forces and the astonishing 2oth Century}

\begin{abstract}
It is intended, from a critical analysis of Benjain Coriat and Ruy Fausto, to clarify how the historical emergency of taylorism-fordism has made difficult the understanding and relevance of Marx's analysis of the productive forces throughout the 2oth century. It is asserted that taylorism-fordism does not apply to Marx's definition of machinery because it actually consists of a "reinvention of manufacture", and that the lack of observation of this fact would have occasioned the difficulties observed in the quoted authors. These difficulties
\end{abstract}

1 Professor do Departamento de Economia da Universidade Estadual Paulista - UNESP - em Araraquara. 
MORAES NETO, B. As forças produtivas em Marx e o surpreendente século XX

manifest themselves in their suggestion (not always explicit) to dispense with the Grundrisse and The Capital, or only The Capital, in order to fully understand the nature of the productive forces in the present and the future - a suggestion that is intended to be criticized.

Keywords: Productive forces; Marxist analysis; manufacture; machinery; Taylorism-Fordism.

JEL : B14, B51, P16

\title{
Introdução
}

Utilizemos a análise de Benjamin Coriat para encaminhar a discussão sobre como a análise feita por Marx acerca das forças produtivas desenvolvidas historicamente pelo capital teria iluminado o entendimento da evolução das forças produtivas ao longo do século XX.

Para Coriat, o século XX teria ilustrado à perfeição as observações de Marx sobre as características do processo de trabalho plenamente ajustado ao regime do capital. O elemento condutor por excelência dessa amarração perfeita entre Marx e o século XX seria o taylorismo (e, obviamente, seu desenvolvimento máximo, ou seja, o fordismo). A noção de uma linha direta Marx-Taylor encontra-se perfeitamente colocada na citação abaixo:

\begin{abstract}
Tudo o que Marx anuncia em relação às características especificamente capitalistas do processo de trabalho (parcelamento das tarefas, incorporação do saber técnico no maquinismo, caráter despótico da direção) o realiza Taylor, ou, mais exatamente, lhe dá uma extensão que até então não havia tido. O excepcional interesse que apresenta Taylor reside no fato de que é a expressão consciente, concentrada $e$ sistemática dos interesses do capital em um momento estratégico de sua história. Torna a burguesia consciente dos imperativos da valorização do capital relativamente às formas que deve imprimir ao processo de trabalho, formas que Marx havia anunciado de maneira dedutiva. (Coriat 1976:107)
\end{abstract}

Essa visão da linha direta Marx-Taylor motivou a significativa brincadeira de Tauile: "A título meramente de ironia, parece que Taylor tinha lido Marx e aplicou suas idéias a favor do desenvolvimento capitalista." (Tauile 2001:97)

É importante observar que a visão fundamental de Coriat de que somente com o taylorismo-fordismo o capital teria achado sua base técnica adequada, elemento crucial de Ciência, técnica y capital, de 1976, será 
mantida e reforçada em toda a sua produção posterior ${ }^{2}$. Em El Taller y el Cronómetro, de 1979, lemos: "O cronômetro entrou na fábrica: indubitavelmente está em marcha a maior revolução da história humana." (Coriat 1982:2)

É muito interessante observar que para Coriat todo o período histórico anterior a Taylor teria sido tomado pelo trabalhador de ofício, possuidor de qualificação de tipo artesanal:

É necessário voltar ao 'melhor dos antigos sistemas' e nos referirmos sobretudo ao principal obstáculo que enfrenta, para apreciar as mudanças que o taylorismo irá realizar. O saber-fazer operário, como temos visto, é este obstáculo. Taylor procede à sua eliminação. Eliminação metódica: primeira questão: de onde procede? Resposta: é conseqüência de uma larga acumulação de saber prático, transmitido oralmente - na fase de aprendizagem - de geração em geração. (...) Transmitido de geração em geração, oralmente e na prática (da aprendizagem), portanto não sistematizado nem codificado, o que constitui a força dos trabalhadores é que a quase totalidade do saber técnico está neles e é de sua posse.(Coriat 1976:93-94)

Com Taylor, no início do século, tudo muda: o 'marca-passo' operário se converte em frente de ataques, até que se consegue limitá-lo. (...) Então, aparece a verdade: o trabalhador de ofício, herdeiro dos 'segredos' do grêmio, segue sendo a condição inevitável, a figura necessária da manufatura. Mais ainda, a indústria, em seu conjunto e enquanto tal, depende dele (grifo nosso). (Coriat 1982:8)

Submeter o trabalhador de ofício, 'liberar' o processo de trabalho do poder que este exerce sobre ele, para instalar em seu lugar a lei e a norma patronais, tal será a contribuição histórica do taylorismo. (Coriat 1982:24)

Após a surpreendente afirmação da prevalência do ofício até o início do século XX, fica uma interessante questão: como este autor incorporaria em seu esquema histórico-teórico a análise feita por Marx sobre a maquinaria? Como se trata de autor ligado a Marx, tal desafio teria de ser enfrentado, e é o que acontece logo no início de El Taller y el Cronômetro:

(...) se bem que a conservação dos 'segredos' no interior da estirpe do mestre seja a exceção, o 'ofício' constituirá de maneira sistemática e geral - durante todo o século XIX a pedra angular sobre a qual será construída a organização operária, sua capacidade de resistência, sua força. (...) a dependência na qual se encontrava o capital no que se refere ao abastecimento de força de trabalho aparece em primeiro lugar

2 Sobre os efeitos da "prisão teórica" ao taylorismo-fordismo para a obra de Benjamin Coriat, confira: SANTOS SILVA, Romildo, 2006: Processo de trabalho e pensamento social no século XX: um estudo da obra de Benjamin Coriat, Tese de Doutorado, Programa de Pós-Graduação em Sociologia, UNESP / Araraquara - SP, 2006 
MORAES NETO, B. As forças produtivas em Marx e o surpreendente século XX

como um limite insuportável. (...) O capital busca inicialmente uma saída através da máquina (grifo nosso). Desde seu surgimento, esta é concebida como um meio de contornar (grifo nosso) as linhas de resistência levantadas pelo ofício. (Coriat 1982:13-16)

Está ficando claro que a saída via máquina não teria resolvido o problema da dependência do capital frente à especial qualificação do trabalho vivo. A não radicalidade da máquina como resposta do capital aos limites postos pelo saber-fazer operário fica explicitado, ainda que nunca explicado: "Desde logo, a máquina pode obriga-lo, porém ao trabalhador adulto permanecem todavia pontos de resistência." (Coriat 1982:17)

Radicalidade na libertação do capital dos limites da qualificação do trabalhador, permitindo finalmente que sua forma técnica adequada seja alcançada, só com Taylor:

\begin{abstract}
O que diferencia Taylor de seus predecessores, no que indiscutivelmente rompe com as práticas anteriores, é o fato de ter constituído o ofício mesmo em frente de ataque, em obstáculo a superar. Não busca a forma de se esquivar (o grifo agora é do autor) como faz a máquina, de 'estimula-lo', como se pretende mediante sistemas salariais cada vez mais sofisticados, nem de dirigi-lo contra si mesmo, como faz o sistema de pagamento por peça, mas sim o meio de destruí-lo como tal. Com isso, Taylor executa uma mudança radical de terreno (grifo nosso), cujo resultado histórico será a concepção do tipo de processo de trabalho que permitirá o impulso da produção em massa. (Coriat 1982:23)
\end{abstract}

Pois bem; a máquina analisada por Marx não teria então existido. Isto porque, para ele, a maquinaria teria representado o estágio final do processo de separação entre concepção e execução, significando que, com sua entrada em cena, o capital teria se tornado radicalmente independente do trabalho qualificado:

O camponês e o artesão independente desenvolvem, embora modestamente, os conhecimentos, a sagacidade e a vontade, como o selvagem que exerce as artes da guerra apurando sua astúcia pessoal. No período manufatureiro, essas faculdades passam a ser exigidas apenas pela oficina em seu conjunto. As forças intelectuais da produção só se desenvolvem num sentido, por ficarem inibidas em relação a tudo que não se enquadre em sua unilateralidade. O que perdem os trabalhadores parciais, concentra-se no capital que se confronta com eles. A divisão manufatureira do trabalho opõe-lhes as forças intelectuais do processo material de produção como propriedade de outrem e como poder que os domina. Esse processo de dissociação começa com a cooperação simples em que o capitalista representa diante do trabalhador isolado a unidade e a vontade do trabalhador coletivo. Esse processo desenvolve-se na manufatura, que mutila o trabalhador, reduzindo-o a uma fração de si mesmo, e completa-se na indústria 
moderna, que faz da ciência uma força produtiva independente de trabalho, recrutando-a para servir ao capital. (Marx 1968:413-414)

Para Marx, portanto, o século XIX teria experimentado um processo de separação entre concepção e execução do trabalho industrial que teria alcançado seu ponto culminante com a grande indústria. Como afirma Palma, "a grande indústria leva ao grau máximo esta cisão (entre trabalho intelectual e trabalho manual), empregando a ciência no processo de trabalho e alienando-a do trabalhador." (Palma 1972:30)

A máquina representa, para Marx, portanto, um momento definitivo no processo de libertação do capital frente ao trabalho qualificado, coisa que também observava com regozijo Andrew Ure em 1835:

Regozijo-me ao ver que a ciência promete agora resgatar este ramo da indústria dos caprichos do trabalho manual e colocá-lo, como os demais, sob o domínio do mecanismo automático.

(Ure 1985:7)

Quando Adam Smith escreveu seus imortais pensamentos de economia, os mecanismos automáticos sendo praticamente desconhecidos, ele foi corretamente levado a encarar a divisão do trabalho como o grande princípio do progresso manufatureiro. (...) Mas o que no tempo do Dr. Smith era um tópico de ilustração útil, não pode agora ser usado sem o risco de confundir a mentalidade pública (comum) no que se refere ao princípio correto da indústria manufatureira. De fato, a divisão do trabalho, ou melhor, a adaptação do trabalho aos diferentes talentos dos homens, é pouco considerada no emprego fabril. Pelo contrário, sempre que um processo requer destreza e firmeza de mãos peculiares, ele é retirado o mais rapidamente possível das mãos do trabalhador habilidoso, que tem tendência a cometer irregularidades de muitos tipos, e é posto sob o comando de um mecanismo específico, tão autosuficiente que até uma criança pode controlar o seu funcionamento. (Ure 1985:16-17)

\section{Também em Mantoux o processo se apresenta de forma clara:}

E isto é a característica da máquina: em lugar de ser um instrumento nas mãos do trabalhador, a máquina é uma mão artificial. Distinguese da ferramenta menos pela força automática que a move do que pelos movimentos de que é capaz, esses movimentos inscritos em sua estrutura pela arte do engenheiro, e que substituem os procedimentos, os hábitos e a destreza da mão. (Mantoux 1962:174)

É necessário enfatizar que, em Marx, a libertação frente à especial qualificação do trabalho vivo se faz, pela via da maquinaria, de forma tão radical, que o capital passa a prescindir não só do saber-fazer, mas do próprio trabalho vivo enquanto tal: 
MORAES NETO, B. As forças produtivas em Marx e o surpreendente século XX

\begin{abstract}
A máquina-ferramenta é portanto um mecanismo que, ao lhe ser transmitido o movimento apropriado, realiza com suas ferramentas as mesmas operações que eram antes realizadas pelo trabalhador com ferramentas semelhantes. (Marx 1968:426)

Quando a máquina-ferramenta, ao transformar a matéria-prima, executa sem ajuda humana todos os movimentos necessários, precisando apenas da vigilância do homem para uma intervenção eventual, temos um sistema automático (...) (Marx 1968:434)

Assim, o processo de produção deixa de ser um processo de trabalho, no sentido em que o trabalho constituiria a sua unidade dominante. (Marx 1978:219)

A ciência manifesta-se, portanto, nas máquinas, e aparece como estranha e exterior ao operário. O trabalho vivo encontra-se subordinado ao trabalho materializado, que age de modo autônomo. Nessa altura, o operário é supérfluo. (Marx 1978:221)
\end{abstract}

Como desdobramento fundamental da noção de superfluidade do trabalho vivo imediato, que se contrapõe à visão da eternização do trabalho desqualificado presente em Smith, tem-se a consideração de Marx da contribuição por excelência do capital: o desenvolvimento de forças produtivas possibilitadoras de uma sociedade socialmente avançada, que consiga realizar a transcendência do trabalho alienado:

O trabalho da produção material só pode adquirir esse caráter (de trabalho realmente livre, emancipado): 1) Se o seu conteúdo se tornar diretamente social; 2) Se se revestir de caráter científico e surgir diretamente como tempo de trabalho geral. Por outras palavras, se deixar de ser o esforço do homem, simples força de trabalho natural no estado bruto tendo sofrido um determinado treinamento, para se tornar a atividade do sujeito que regula todas as forças da natureza no seio do processo de produção. (Marx 1978:120)

Este desdobramento fundamental da produção à base de maquinaria teria ocorrido porque, para Marx, "cessou de existir o trabalho no qual o homem faz aquilo que pode conseguir que as coisas façam em seu lugar" (Marx 1978 apud Rosdolsky 1985:468). É a partir daí que Marx pôde extrair sua consideração crucial de que o capitalismo, medíocre enquanto forma social, possui um caráter brilhante no que diz respeito ao desenvolvimento das forças produtivas.

Retornemos a Coriat. Já mencionamos que, para ele, a máquina do século XIX não teria tido nenhum caráter radical, pois não passaria de um arremedo de libertação do trabalho qualificado pelo capital, coisa que só viria efetivamente com Taylor. Se chamarmos o taylorismofordismo de "maquinaria do século XX", coisa plenamente ajustada à visão de Coriat, então poderíamos avaliar se, de acordo com este autor, o que teria se passado seria apenas um diferimento histórico da máqui- 
na de Marx. Esta seria uma alternativa histórico-teórica inteiramente de acordo com a primeira citação que fizemos de Coriat, na qual se afirma que, "tudo o que Marx anuncia com relação às características especificamente capitalistas do processo de trabalho o realiza Taylor, ou mais exatamente,lhe dá uma extensão que até então não havia tido" (Coriat 1976:107)

Todavia, o que verificamos é que Coriat, ao explicitar as características da "maquinaria do século XX", é bastante feliz, permitindo visualizar com clareza que a mesma não é a máquina de Marx:

Ao acabar com o controle operário sobre os modos operatórios, ao substituir os 'segredos' profissionais por um trabalho reduzido à repetição de gestos parcelares - em poucas palavras, ao assegura a expropriação do saber operário e sua confiscação pela direção da empresa - o cronômetro é, antes de tudo, um instrumento político de dominação sobre o trabalho. Tecnologia e tática pormenorizada do controle dos corpos no trabalho, o taylorismo vai se transformar num verdadeiro 'conjunto de gestos' de produção (grifo nosso), em um código formalizado do exercício do trabalho industrial, com a Organização Científica do Trabalho. (Coriat 1982:2)

Do ponto de vista do trabalho concreto, a 'novidade' introduzida pela scientific management refere-se antes de tudo ao fato de que o controle operário sobre os modos operatórios é substituído pelo que se poderia chamar um 'conjunto de gestos' de produção, concebidos e preparados pela direção da empresa, e cujo respeito é vigiado por ela.

(Coriat 1982: 36)

Para os trabalhadores, a linha de montagem significa confusão, fadiga suplementar, desordem. (...) Porém essa desordem é apenas superficial. Ou talvez não seja mais do que a aparência necessária na qual se expressam as novas leis de bronze do capital, já que também: 'Era como nos filmes onde as imagens se sucedem numa velocidade surpreendente. (...) Se chegava a uma velocidade de gestos assombrosa (grifo nosso). (Coriat 1982:43)

Ainda que jamais se dê conta disso, Coriat, com sua ênfase nos "gestos de produção", explicita com clareza o caráter medíocre da forma taylorista-fordista de organizar o processo de trabalho, coisa que temos enfatizado em trabalhos anteriores, e que pode ser sintetizada na frase seguinte:

A partir da correta compreensão conceitual da maquinaria, a entrada em cena, no século XX, do taylorismo-fordismo é, sem dúvida, causadora de perplexidade. Quem estuda o taylorismo-fordismo observa que, no fundo, o que Taylor tenta fazer é transformar novamente o homem num instrumento de produção, analogamente ao que se havia tentado na fase pré-maquinaria. Essa visão do homem como instrumento de produção magnifica-se no fordismo. Ao encetar sua típica inovação, que é a linha de montagem, Ford não fez outra coisa senão coletivizar o 
MORAES NETO, B. As forças produtivas em Marx e o surpreendente século XX

taylorismo, com o recurso fundamental da esteira, que procura resolver o problema tipicamente manufatureiro do transporte. Na verdade, esta grande fábrica fordista, ao invés de significar a indústria por excelência, a forma mais avançada da produção capitalista, significou, isto sim, uma 'reinvenção da manufatura', uma coisa extremamente atrasada do ponto de vista conceitual, a despeito de seu imenso sucesso do ponto de vista econômico, produtivo. A colocação de milhares de trabalhadores, uns ao lado dos outros, fazendo movimentos parciais, de forma alguma ajusta-se à noção marxista de produção à base de maquinaria. (...) A grande indústria fordista não significa, portanto, uma ilustração do conceito marxista de grande indústria; na verdade, significa a sua negação.(...) $O$ caminho do taylorismo-fordismo significa, na verdade, um 'desvio mediocrizante' do capitalismo no que se refere ao desenvolvimento das forças produtivas, amplamente vinculado à indústria metal-mecânica. Afinal, não é nada brilhante colocar o ser humano em atividades sem conteúdo e medir seus tempos e movimentos como um instrumento de produção, assim como não é nada brilhante colocar milhares de pessoas, umas ao lado das outras, fazendo movimentos repetitivos. Isto não tem nada a ver com a utilização da ciência como força produtiva, não faz jus à colocação de Marx acerca do brilhantismo do capitalismo quanto ao desenvolvimento das forças produtivas. (Moraes Neto 2003:124-125)

Esta visualização permite refazer as linhas de ligação entre os autores dos séculos XVIII e XIX e Taylor e Ford. A primeira linha direta vai de Babbage a Taylor, coisa que se depreende desde logo da preocupação do primeiro, em 1832, com aquilo que foi a obsessão do segundo, qual seja, as características particulares do ser humano como instrumento de produção, a conhecida "barreira orgânica" sobre a qual nos adverte Marx para a produção manufatureira:

A fadiga produzida nos músculos do corpo humano não depende completamente da força efetivamente empregada em cada esforço, mas parcialmente da freqüência através da qual ela é exercida. O esforço necessário para realizar cada operação consiste de duas partes: uma delas é o gasto de força que é necessário para guiar a ferramenta ou instrumento; e a outra é o esforço requerido para a movimentação de algum membro do animal que produz a ação. Ao pregar um prego num pedaço de madeira, uma delas é erguer o martelo e impelir sua cabeça contra o prego; a outra é levantar o próprio braço, e movimenta-lo no sentido de usar o martelo. Se o peso do martelo é considerável, a primeira parte irá causar a maior porção do esforço. Se o martelo é leve, o esforço de levantar o braço irá produzir a maior parte da fadiga. Acontece portanto que aquelas operações que requerem uma força muito insignificante, se freqüentemente repetidas, irão cansar de modo mais efetivo do que o mais laborioso trabalho. Existe também um grau de rapidez além do qual não se pode forçar a ação dos músculos. (...) A proporção entre a velocidade através da qual homens ou animais se movem, e os pesos que carregam, é uma matéria de importância considerável, principalmente em assuntos militares. É também de 
grande importância para a gestão do trabalho fazer o ajuste entre o peso daquela parte do corpo do animal que se movimenta, o peso da ferramenta, e a freqüência de repetição desses esforços, de modo a produzir o melhor efeito. (...) Sempre que o trabalho é leve, torna-se necessário, de modo a economizar tempo, incrementar a velocidade. (Babbage 1971:30-32)

A segunda linha direta vai, obviamente, de Smith a Ford, posto que a inovação fundamental do segundo caracteriza-se como uma "reinvenção da manufatura" ${ }^{3}$. Esse caráter smithiano da linha de montagem fordista pode ser imediatamente visualizado a partir de relato recente de trabalho na China de nossos dias:

Na fábrica de bicicletas Dahon, em Shenzhen, os dedos de Zhang Jingming se movem ágil e metodicamente apanhando selins de bicicleta, envolvendo-os em papel-cartão e afixando-os à estrutura em um movimento fluido. Zhang trabalha 45 horas por semana e seu salário equivale a US\$ 263 mensais. Até fevereiro, ele ganhava só US\$ 197. Parte de seu aumento deriva do ganho de eficiência que conseguiu. “Quando comecei, eu não era tão rápido”, diz. (Bradsher 2007)

De novo, voltemos a Coriat, fazendo um balanço da situação em que nos encontramos. A maquinaria analisada por Marx só se efetivaria no século XX, com o taylorismo-fordismo. Até aí, poder-se-ia, por um lado, creditar a Marx grande poder analítico-premonitório, pois, se bem seus argumentos não se aplicassem ao momento das forças produtivas do século XIX, os mesmos teriam encontrado seu rebatimento histórico já nos primeiros momentos do século XX. Contudo, esta "maquinaria do século XX" não é, em absoluto, a máquina de Marx do século XIX, mas sim uma medíocre reinvenção histórica do passado manufatureiro, inteiramente superado pela máquina segundo a visão de Marx. Conclusão inevitável: para Coriat, a brilhante análise das forças produtivas especificamente capitalistas feita por Marx simplesmente não encontraria jamais seu rebatimento histórico! Esta não é a opinião de Coriat, é claro, para quem a máquina de Marx está em Taylor-Ford. Esta forma de ver, por um lado destrói o caráter auto-contraditório do capital presente em Marx, e, por outro, põe uma questão séria à análise de Marx: o que fazer com ela em nossos dias, a partir do fato de que a revolução tecnológica do final do século XX pôs por terra o taylorismo-fordismo? Se caminharmos com Coriat, teremos que nos desfazer de Marx para dar conta do presente e do futuro. Todavia, o que se observa é justamente o opos-

3 Este é o fio condutor de nosso artigo “Automação e trabalho: Marx igual a Adam Smith?” (Moraes Neto 2003) 
to: Marx se transformou numa referência fundamental para o entendimento conceitual do atual estágio das forças produtivas. Realmente, Benjamin Coriat foi vitimado pela surpresa pregada pelo século XX em termos de processo de trabalho, ou seja, pelo fenômeno do taylorismofordismo.

Lembrando nosso primeiro passo: numa tentativa de fornecer imenso poder analítico a Marx, Coriat nos informa que sua "antevisão" teria se materializado em Taylor. Esta forma de ver - linha direta Marx - Taylor - acaba por tirar toda força teórica de Marx, pois não só não existe a máquina de Marx em Taylor, como o taylorismo-fordismo encontra-se em processo de extinção desde as duas últimas décadas do século XX no capitalismo desenvolvido. A relação da análise das forças produtivas efetuada por Marx com o século XX deve, a nosso juízo, ser posta de forma completamente diferente, coisa que temos tentado fazer em alguns trabalhos anteriores. Antes, todavia, de tentar esclarecer esse ponto, vale lembrar uma outra tentativa de buscar o rebatimento da análise das forças produtivas em Marx e o século XX, devida a Ruy Fausto. Como já tratamos disso em texto anterior (MORAES NETO, 2005), vamos procurar caminhar de forma mais rápida aqui. Trata-se de separar as análises de Marx em $O$ Capital (grande indústria) e nos Grundrisse ("pós-grande indústria"), sendo a primeira mais "realista", ou seja, ajustada à natureza das forças produtivas do século XIX (que teriam se prolongado ao longo dos primeiros dois terços do século XX), e a segunda apresentando um caráter profético, pois apenas teria seu rebatimento histórico a partir do último terço do século XX, com a emergência da automação de base microeletrônica. Ao tentar entender essa forma de ver, nos deparamos com o seguinte fato: o taylorismo-fordismo teria tido grande responsabilidade nessa dualização da análise marxiana. Em nossa forma de ver, Ruy Fausto teria assumido o ajuste perfeito entre a grande indústria de $O$ Capital e o taylorismo-fordismo pelo fato de ter feito uma homologia entre a cooperação simples de máquinas vista por Marx em $O$ Capital (...) e a linha de montagem fordista. Isto se observa com clareza a partir da afirmação do autor de que a característica fundamental da base técnica da grande indústria seria a permanência do trabalho vivo imediato como elemento produtivo fundamental: "Até a grande indústria, a massa de tempo de trabalho, o quantum de trabalho, é o elemento decisivo." (Fausto 1989:50) “(...) até a grande indústria, a riqueza dependia do trabalho." (Fausto 1989:62)

No mencionado texto anterior, procuramos identificar essa forma de ver de Ruy Fausto com o que ocorre tipicamente naquilo que Marx chama de "cooperação simples de máquinas". Este padrão, ilustrado à perfeição pelo tear mecânico, implicaria na designação permanente de um homem como apêndice de uma máquina, perpetuando a subordinação material do trabalho ao capital. Vimos também no mencionado tex- 
to que esse padrão conflita com o que Marx denomina "sistema de máquinas", no qual impera o princípio da continuidade, quando a noção de superfluidade do trabalho vivo se mostra com clareza. Pois bem. Como Marx nos avisava que a máquina sofreria constante aperfeiçoamento, não era necessário imaginar (como ele mesmo parece fazer em alguns momentos) que o padrão "um homem - uma máquina" fosse se eternizar, sendo possível pensar (como efetivamente aconteceu) que um homem pudesse supervisionar $n$ máquinas, quando então a noção de prescindibilidade do trabalho vivo imediato também encontraria um locus apropriado. Acreditamos que, sem a emergência histórica do taylorismo-fordismo, o progresso tecnológico faria cair por terra a idéia de uma eternização da apendicização do trabalho à maquina. Com a entrada em cena, em grande estilo, da proposta taylorista-fordista de organização do processo de trabalho, totalmente impregnada de "gestos de produção", para lembrar Coriat, a idéia de que na "grande indústria" existiria uma dependência absoluta frente ao trabalho vivo imediato surge com grande força, e impregnada de sentido, ainda que só na aparência. Vem daí nossa opinião de que também Ruy Fausto possui uma forma de ver a história das forças produtivas determinada pelo fenômeno do taylorismo-fordismo.

Fazendo um balanço rápido dos desdobramentos advindos das opiniões dos dois autores aqui comentados, observamos que, para Coriat, teríamos que nos desfazer de toda a obra de Marx para dar conta das forças produtivas no presente e no futuro, dada a emergência da nova automação, flexível, de base microeletrônica; já para Ruy Fausto, teríamos que nos desfazer "apenas" de $O$ Capital, sendo preservada a análise realizada nos Grundrisse. Marquemos nossa opinião discordante das dos autores em estudo:

(...) a nova automação, de base microeletrônica, 'explode' esta forma de produção [taylorismo-fordismo], não genérica, mas localizada principalmente na grande indústria metal-mecânica, fundamental em todo o processo de acumulação de capital ao longo do século XX. Essa nova automação significa uma abrupta, concentrada no tempo, recuperação do capital de seu brilhantismo quanto ao desenvolvimento das forças produtivas. Portanto, ao invés de dizer, como Augusto Marzagão, que a 'explosão' da grande indústria Taylor-fordista significa o enterro da análise marxista, devemos, pelo contrário, considerar que ela significa o renascimento da análise marxista. Isto porque chegaremos, de forma genérica, homogênea a toda atividade industrial, a um elevadíssimo grau de cientificização dos processos produtivos. A produção será então, em todas as esferas da indústria, uma 'aplicação tecnológica da ciência', exatamente como afirmara Marx. Isto implica na volta triunfal da questão, crucial para Marx, da contradição entre forças produtivas e relações de produção, posta pelo desenvolvimento do modo de produção capitalista. Essa 'capacidade' do capital de se mover de maneira auto-contraditória é negada pelo taylorismo-fordismo. O 
MORAES NETO, B. As forças produtivas em Marx e o surpreendente século XX

taylorismo-fordismo nega a contradição entre forças produtivas e relações de produção. A constituição de 'macro-fábricas', empregando milhares de trabalhadores parciais, desqualificados, seria a forma de o capital se eternizar, seria a eternização da forma social capitalista, pois a função social do capital estaria preservada. O contrário ocorre quando o capital 'explode' a base Taylor-fordista e avança pelo seu caminho inexorável de desenvolvimento das forças produtivas, pois aí ele caminha no sentido da negação da sua natureza.”

(Moraes Neto 2003:126)

\section{Referências}

BABBAGE, Charles (1971) [1832] On the Economy of Machinery and Manufactures. New York: Augustus M. Kelley Publishers.

BRADSHER, Keith (2007) "Escassez de trabalhadores qualificados eleva os salários na China”. Folha de São Paulo, o8 de setembro (traduzido do New York Times por Paulo Migliaci).

CORIAT, Benjamín (1976) Ciencia, técnica y capital. Madrid: H. Blume Ediciones.

CORIAT, Benjamín (1982) El taller y el cronómetro: Ensayo sobre el taylorismo, el fordismo y la producción en masa. México: Siglo Veintiuno Editores.

FAUSTO, Ruy (1989) “A 'pós-grande indústria' nos Grundrisse (e para além deles). Lua Nova: 19: 47-67

MANTOUX, Paul (1962) La revolución industrial en el siglo XVIII. Madrid: Aguilar.

MARX, Karl. (1968) [1867] O Capital. Rio de Janeiro: Editora Civilização Brasileira.

MARX, Karl. (1978) [1939] Elementos fundamentales para la crítica de la economía política (Grundrisse) 1857-1858., $7^{\mathrm{a}}$ ed. México: Siglo Veintiuno.

MARZAGÃO, Augusto (1997) “O horror dos excluídos”. Folha de São Paulo, 04 de setembro.

MORAES NETO, Benedito de (2003) Século XX e trabalho industrial: Taylorismo/ fordismo, ohnoísmo e automação em debate. São Paulo:Xamã Editora.

MORAES NETO, Benedito de (2005) "Observações sobre os Grundrisse e a história dos processos de trabalho". Revista da Sociedade Brasileira de Economia Política 16: 7-31.

PALMA, Armando (1972) "La organización capitalista del trabajo en El Capital de Marx" In PALMA, A . et al. La división capitalista del trabajo. Córdoba: Cuadernos de Pasado y Presente 32.

ROSDOLSKY, Roman (1985) Genesis y estructura de El Capital de Marx. México: Siglo Veintiuno Editores.

SANTOS SILVA, Romildo (2006) Processo de trabalho e pensamento social no século XX: um estudo da obra de Benjamin Coriat. Araraquara- SP: tese de 
MORAES NETO, B. As forças produtivas em Marx e o surpreendente século XX

doutorado, Universidade Estadual Paulista (UNESP), Programa de PósGraduação em Sociologia.

TAUILE, José Ricardo (2001). Para (re)construir o Brasil contemporâneo. Rio de Janeiro: Contraponto.

URE, Andrew (1985) [1835] The Philosophy of Manufactures. London (Primeiro capítulo traduzido por William Asbury, Universidade Federal de São Carlos, mimeo). 